\title{
Microplastics in beach sand and potential contamination of planktivorous fish Sardinella gibbosa inhabiting in coastal waters of Negombo, Sri Lanka
}

\author{
R. R. M. K. P. Ranatunga*, D. S. Wijetunge and K. P. R. Karunarathna \\ Centre for Marine Science and Technology, Department of Zoology, University of \\ Sri Jayewardenepura, Nugegoda, Sri Lanka
}

*Correspondence (ranatunga@sci.sjp.ac.lk)

https://orcid.org/0000-0002-0432-6003

Received: 20.07.2020Ｒevised: 08.02.2021 Accepted: 27.02.2021 Published online: 15032021

\begin{abstract}
Microplastic pollution has become the most significant marine environmental concern. There has been a surge of information on microplastic contamination in various marine environments worldwide. However, the level of microplastic contamination in marine environments is just begun to understand in Sri Lanka. The present study looked at the microplastic contamination level in the beach sand of Pitipana, Catamaran, and Dūwana beaches along the coast of Negombo, Sri Lanka. Sampling was conducted bi-monthly from March to November in 2017. Beach sand samples were collected from the surface $(0$ $1 \mathrm{~cm})$ and subsurface $(10-11 \mathrm{~cm})$ layers and three regions representing the low-tide, high-tide, and vegetation line of each beach. Sand samples were filtered through $5 \mathrm{~mm}$ and $1 \mathrm{~mm}$ sieve-set, and particles greater than $5 \mathrm{~mm}$ were discarded since they are not considered microplastics. Particles retained in $1 \mathrm{~mm}$ sieve and the filtrate were collected separately. Microplastics were density separated and categorized into two size classes as $1-5 \mathrm{~mm}$ and smaller than $1 \mathrm{~mm}$. Microplastics in the 1-5mm size-class were categorized as fiber, foam, fragment, and pellet. Microplastics < $1 \mathrm{~mm}$ were subjected to FTIR spectroscopy and identified based on the polymer type. Further, goldstrip sardine, Sardinella gibbosa samples were obtained from the coastal waters of Pitipana and tested for possible microplastic contamination in commercial fishes. Results revealed that the Pitipana beach sand was highly contaminated with $1-5 \mathrm{~mm}$ category microplastics reporting a mean abundance $( \pm \mathrm{SD})$ value of $7.2 \pm 7.66$ particles $/ \mathrm{m}^{3}$ by number compared to other sites. The fragment was the dominant type found in Catamaran and Dūwana beaches, while foam was the predominant type in Pitipana beach. However, pellets were not recorded in any of the sites sampled. Polyvinyl chloride (PVC) was the major polymer type recorded in Pitipana beach sand, and polyester was dominant in Dūwana and Catamaran beaches. The FTIR spectra revealed the presence of polyethylene and polypropylene in gut contents of Sardinella gibbosa, suggesting contamination of microplastics in planktivorous fish and potential for accumulation along the trophic chain.
\end{abstract}

Keywords: Microplastics, beach sand, Negombo, Sri Lanka, fish contamination

\section{INTRODUCTION}

The occurrence of microplastics in coastal and marine habitats is a global concern and trending in research due to their ubiquitous nature and potential deleterious impacts on marine life (GESAMP 2015; Hanke et al. 2013; Hidalgo-Ruz et al. 2012). In 1950, approximately 1.7 million tons of plastics were produced, and ever since, there has been an exponential growth (PlasticEurope 2016). In 2018, global plastics production was reported as 360 MTs, and Asia was the major plastic producing region contributing $51 \%$ to global production (PlasticEurope 2019). Specific properties of plastics such as durability, lightweight, inexpensive, and high specific strength, make plastic chosen over other materials (Jang et al. 2017).

First records of plastic pollution in the ocean appeared in the scientific literature in the early 1970s (Carpenter et al., 1972), with increasing reports continuing through time (Bonin et al. 2014; Jambeck et al. 2015; Jang et al. 2017). According to PlasticEurope (2019), out of the collected postconsumer plastic waste, $32.5 \%$ is being recycled, $42.6 \%$ is being used for energy recovery, and $24.9 \%$ ends up in landfills.

Plastics are mainly categorized into two size classes as macroplastics and microplastics (Browne et al. 2011; Kunz et al. 2016). Lee et al. (2013) defined macroplastics as plastics larger than $25 \mathrm{~cm}$ and plastics smaller than $5 \mathrm{~mm}$, as microplastics. 
"Mesoplastics" are another category in between macro and microplastics $(5 \mathrm{~mm}-25 \mathrm{~mm})$ that are not too large yet not too small (Andrady 2011; Lee et al. 2013).

The size of microplastics is defined variedly by different scientists. According to Hidalgo-Ruz et al. (2012), the term "microplastics" has been used in 2004 for the first time, referring to tiny fragments of plastic $(\sim 50 \mu \mathrm{m})$ in the water column and sediments. Graham and Thompson (2009) stated microplastics arbitrarily as plastic particles with diameters of $<10 \mathrm{~mm}$, Ryan et al. (2009) as $<2 \mathrm{~mm}$, and in Browne et al. (2011) and Claessens et al. (2011) as $<1 \mathrm{~mm}$. However, a descriptive definition for microplastics was given by Gago et al. (2018) as "any synthetic solid particle or polymetric matrix, with regular or irregular shape and with size ranging from $1 \mu \mathrm{m}$ to $5 \mathrm{~mm}$, of either primary or secondary manufacturing origin, which are insoluble in water can be termed as "microplastics". Therefore, plastic particles of less than $5 \mathrm{~mm}$ have generally termed microplastics (NOAA 2008; Betts 2008; Barnes et al. 2009; Andrady 2011; Yu et al. 2016).

Though a broader discussion has begun within the last decade, the existence of micro-sized synthetic polymers in marine and coastal environments has been in records for nearly five decades (Buchanan 1971; Carpenter et al. 1972; Carpenter and Smith 1972; Colton and Knapp 1974). The occurrence of microplastics in surface water of the open ocean and marine shorelines (Law et al. 2010; Collignon et al. 2012; Goldstein et al. 2012; Ivar do Sul et al. 2013; Browne et al. 2011; Santos et al. 2009), in estuaries (Sadri and Thompson 2014), in sub-tidal sediments and deepsea sediments (Van Cauwenberghe et al. 2013; Woodall et al. 2014; Browne et al. 2011), in Arctic sea ice (Obbard et al. (2014) and also in marine biota (Van Cauwenberghe et al. 2015; Wright et al. 2013) has been reported over the years.

Microplastics' origin provides essential information about the potential sources of the pollutant and supports finding mitigation measures (GESAMP 2015). Primary microplastics and secondary microplastics are grouped based on the origin whether they are manufactured to be in that size or broken particles of the larger items (Rodr1'guez-Seijo and Pereira 2017). Virgin plastic pellets $(2-5 \mathrm{~mm}$ in diameter) are also considered as primary microplastics (Andrady 2011; Costa et al. 2010) and are mostly used in facial-cleansers and cosmetics (Zitko and Hanlon 1991), in medicine as vectors for drugs (Patel et al. 2009), as air-blasting media (Gregory 1996), etc. Secondary microplastics originate due to the cumulative effect of physical, biological, and chemical processes reducing the structural integrity of plastic debris, causing fragmentation over time. Exposure to Ultraviolet radiation for prolonged periods may lead to photodegradation of plastics, increasing susceptibility to fragmentation (Moore 2008; Andrady 2011). In the aquatic environment, fragmentation is induced by abrasion, wave-action, and turbulence (Barnes et al. 2009). Such microplastics can further degrade into nano plastics particles.

Microplastics can be further categorized based on the geometry, colour, polymer type, density, etc. (Hidalgo-Ruz et al. 2012; Rodr1'guez-Seijo and Pereira 2017). Commonly identified geometrical shapes include fragment, film, pellet, fiber and foam. The type/shape of a microplastic particle is important in identifying the potential to be swallowed by an organism, and it may describe the magnitude of physical harm(s) caused (Rodr1'guezSeijo and Pereira 2017). Colour of the microplastic particle is essential in visual identification among other debris. It is also crucial in identifying the potential to be swallowed by a visual predator and provides information on chemical composition, potential sources and the amount of degradation (Imhof et al. 2016; Castro et al. 2016). Density determines the bioavailability of microplastics in different habitats and may also provide information about threatened groups of organisms (Duis and Coors 2016; Rodri'guez-Seijo and Pereira 2017). Density is important in knowing the chemical buildup, the polymer type. Using the polymer type in identification is more scientific, accurate, and essential in identifying potential sources (Rodr1'guez-Seijo and Pereira 2017). Different spectroscopic identification methods such as Fourier-Transform Infrared Radiation (FTIR) spectroscopy, near-infrared spectroscopy, and Raman spectroscopy are prominently used (Hidalgo-Ruz et al. 2012; Song et al. 2015; Wieczorek et al. 2018). Categorizations of microplastics vary according to the description; therefore, different authors have provided different classifications. Lack of standard classification and descriptions makes it challenging to compare studies with different pollution status. Therefore, establishing global standards in definitions and 
methodologies will create effective scientific communication regarding microplastics.

Apart from the direct human involvement in beaches, estuaries, and other land use activities on the coast that acts as carriers of plastic pollutants from land, ever-changing currents in the open ocean bring marine plastics back to the coastal environment. These plastics and microplastics pose detrimental effects on the aquatic environment and life. According to Balasubramaniam and Phillott (2016), microplastics may alter heat transfer and water movement in beaches. The major impacts of microplastics on aquatic biota include possible ingestion, reduced health and decreased fecundity (Lenz et al. 2016), bioaccumulation, and mortality (Hardesty and Wilcox 2011; Jayasiri et al. 2013; Balasubramaniam and Phillott 2016). A range of marine biota, including zooplankton, seabirds, crustaceans, molluscs, and fish, have been reported to have ingested microplastics in their bodies (Blight and Burger 1997; Tourinho et al. 2010; Lenz et al. 2016; Wieczorek et al. 2018; Wijethunga et al. 2018).

When finding solutions to this menace, Sri Lanka stays far behind in scientific efforts on identifying the issue. Microplastic research plays a vital role in determining the nature of the issue and support in quantifying impacts. Most investigations focus on the abundance, sources, distribution, and impacts of microplastics (Yu et al. 2018). The first evidence of microplastic contamination in Sri Lanka was recorded in 2017 in beach sand from Negombo (Ranatunga and Karunarathna, 2018). Since then, Sri Lanka is progressing forward with various microplastic studies conducted in western and southern coasts (Ranatunga and Karunarathna 2018; Koongolla et al. 2018; Weerakoon et al. 2018; Viraj et al. 2019), in the Kelani river estuary (Thakshila and Ranatunga 2019), in coastal waters (Weerakoon et al. 2019; Athapaththu et al. 2019; Meegahakotuwa et al. 2020; Athawuda et al. 2020), in sessile invertebrates (Wijethunga et al. 2018) and Marine Protected Areas (Dharmadasa et al. 2019). The present study was started in 2016 as the pioneer effort in microplastics research in order to test the contamination of microplastics in Sri Lankan coasts.

\section{METHODOLOGY}

\section{Study site}

Dūwana, Catamaran and Pitipana beaches in the Negombo area along the west coast of Sri Lanka were selected for the study considering different land-use patterns (Figure 1). Pitipana $\left(7^{\circ} 10^{\prime} 34.3^{\prime \prime} \mathrm{N}\right.$, $79^{\circ} 49^{\prime} 20.7^{\prime \prime} \mathrm{E}$ ) is quite a narrow sandy beach isolated from human activities where Catamaran $\left(7^{0} 15^{\prime} 15.7^{\prime \prime} \mathrm{N}, 7^{\circ} 50^{\prime} 26.7^{\prime \prime} \mathrm{E}\right)$ is a wide sandy beach with lots of fishery and tourism-related activities. Dūwana $\left(7^{0} 16^{\prime} 14.6^{\prime \prime} \mathrm{N}, 7^{\circ} 50^{\prime} 31.0^{\prime \prime} \mathrm{E}\right)$ is a wide sandy beach associated with the Maha Oya estuary. Maha Oya is one of the major river basins in Sri Lanka, consisting of $1528 \mathrm{~km}^{2}$ catchment area. The river's lower reach is densely populated (708 persons per $\mathrm{km}^{2}$ ), urbanized, and occupied by industries like clay and sand mining. These affect the river morphology as well as continuous water quality degradation (Weerakkody 2006). Since Negombo is one of the major commercial hubs in Sri Lanka reputed for tourism, fishing industry, and key coastal, ecological features such as estuaries, mangroves, reefs, etc., it is of high importance to investigate the magnitude of pollution from microplastics in the area. 


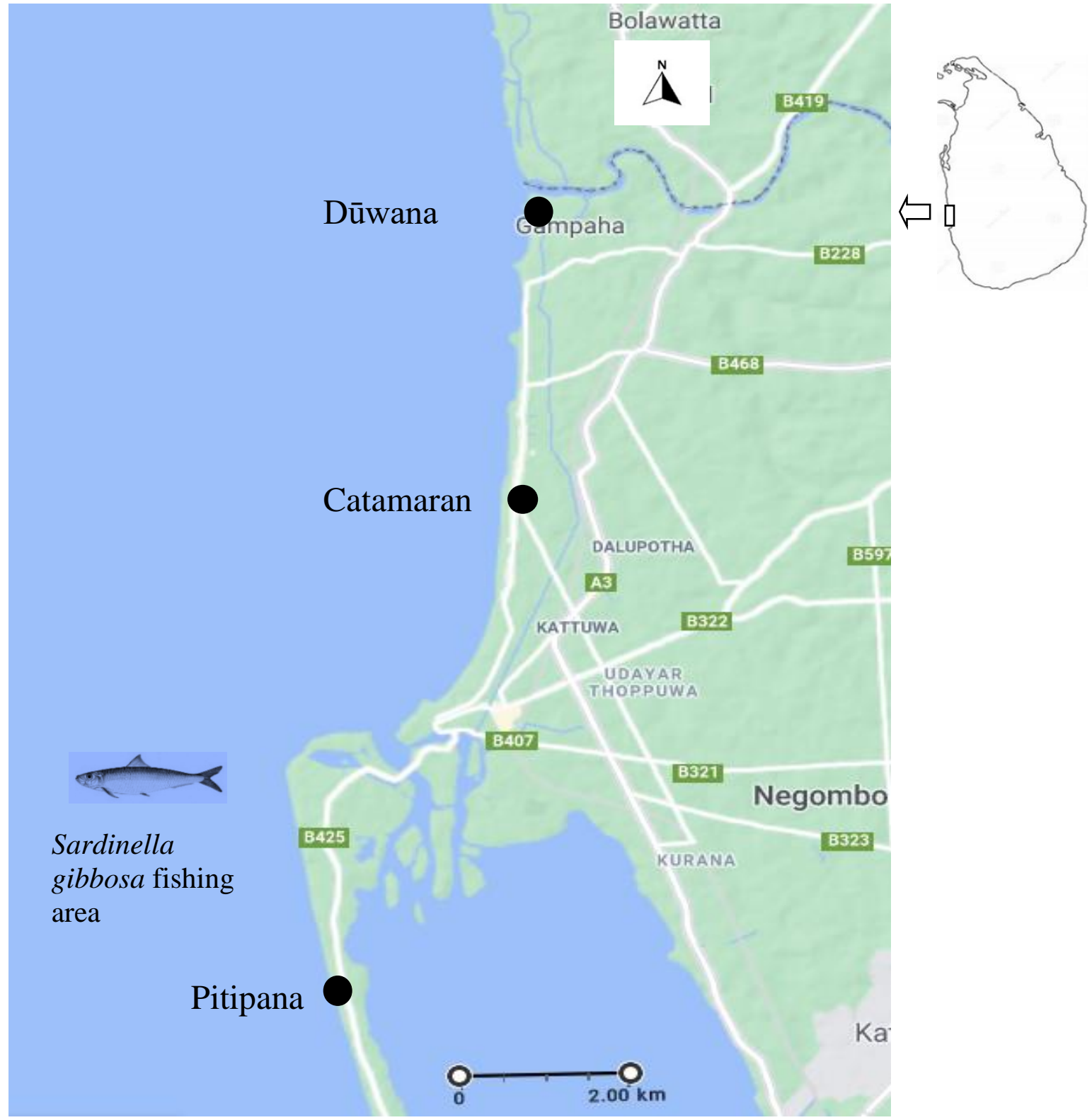

Fig 1 Map showing the beach sand and fish sampling locations.

\section{Sample collection}

Beach sampling was conducted bi-monthly from March to November 2017 in all three locations. Three line-transects of $20 \mathrm{~m}$ length were plotted in the vegetation, high-tide and low-tide regions parallel to the shore (Figure 2). A $30 \mathrm{~cm} \times 30 \mathrm{~cm}$ quadrat was placed randomly in each line-transect to collect sand samples with a duplicate. A metal hand shovel and a core sampler were used in surface $(0-1 \mathrm{~cm})$ and subsurface $(10-11 \mathrm{~cm})$ sampling, respectively. Two surface sand samples and two subsurface sand samples were collected from each line-transect within vegetation and high-tide regions. Only two surface sand samples were collected from the low-tide region due to continuous inundation in the area. Operating the core sampler avoiding inundation was difficult, and also continuous wave action might give erroneous results by adding new microplastic particles to the sample. Collected sand samples were securely transported without contamination and stored in closed glass beakers until processing. 


\section{BEACH}

Vegetation line

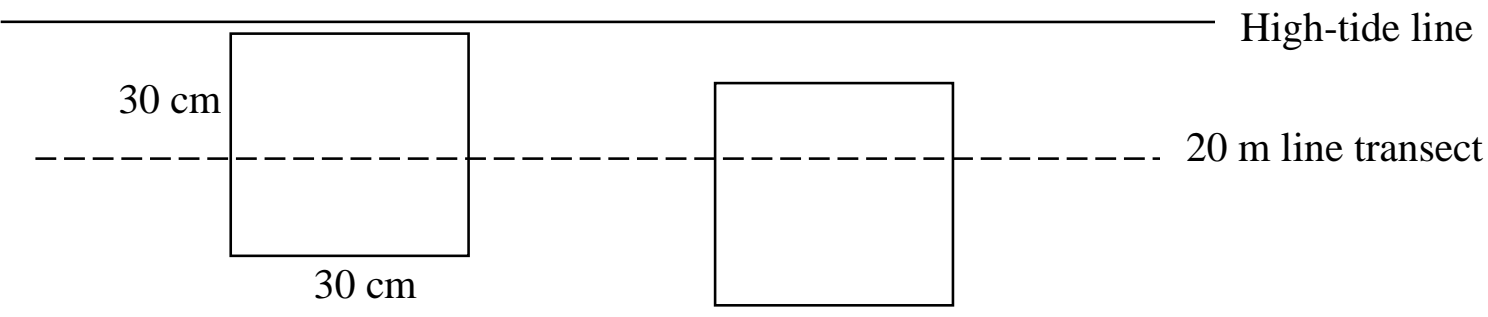

Low-tide line

\section{SEA}

Fig 2 Sampling plan for beach sand in each location

Fish samples of goldstrip sardine, Sardinella gibbosa (30 numbers) were collected from local fishers fishing in Pitipana coastal waters. Samples were cleaned and refrigerated in glass containers until processing to minimize contamination.

\section{Sample preparation}

Beach sand samples were oven-dried at a temperature of $60^{\circ} \mathrm{C}$ for $60-120$ minutes until the samples completely dry out (Modified method of Nuelle et al. 2014). Oven-dried samples were sieved against two sieves with $5 \mathrm{~mm}$ and $1 \mathrm{~mm}$ mesh sizes to separate available microplastics into two size classes (1-5mm and <1 $\mathrm{mm}$ ) (Modified from Hanke et al. 2013). Particles greater than $5 \mathrm{~mm}$ were discarded. Particles retained on the $1 \mathrm{~mm}$ sieve (1$5 \mathrm{~mm}$ category) and the filtrate $(<1 \mathrm{~mm}$ category) were collected separately for microplastics investigation. Microplastics of $1-5 \mathrm{~mm}$ were observed using a stereomicroscope (Nikon SMZ $1270 \mathrm{i})$ and a hand lens. Microplastics of $<1 \mathrm{~mm}$ size were prepared for further investigation (Modified from Hanke et al. 2013).

Density separation was performed in order to extract $<1 \mathrm{~mm}$ category microplastics from the sediment. The $100 \mathrm{ml}$ of saturated $\mathrm{NaCl}$ solution (Density-1.2 $\mathrm{gcm}^{-3}$ ) was added to $50 \mathrm{ml}$ of the sediment sample in a $250 \mathrm{ml}$ volumetric flask and gently but thoroughly mixed for 5-10 min. The mixture was kept still on a flat surface for $30 \mathrm{~min}$, and the supernatant was poured carefully into a labeled $500 \mathrm{ml}$ glass volumetric flask. The step was repeated, and the supernatant was collected. $100 \mathrm{ml}$ of saturated $\mathrm{NaI}$ (with density $1.8 \mathrm{gcm}^{-3}$ ) was added to the sample to ensure the denser microplastics are extracted. The mixture was allowed to settle, and the supernatant was collected to the $500 \mathrm{ml}$ volumetric flask. This step was repeated once again in order to make sure all the microplastic particles in the sample were correctly extracted. $30-50 \mathrm{ml}$ of $30 \% \mathrm{H}_{2} \mathrm{O}_{2}$ was added to the microplastics sample to remove organic materials. The solution was mixed well and kept for nearly seven days until all biological materials were digested (Modified method of Nuelle et al. 2014). After seven days of digestion, vacuum filtration was performed to separate microplastics from the solution. GF/C filter papers of $1.2 \mu \mathrm{m}$ pore size were used in vacuum filtration. Filter papers were then oven-dried at 40$50^{\circ} \mathrm{C}$, and stored in glass petri dishes until the enumeration is done.

Gut contents of 30 Sardinella gibbosa individuals were used to investigate possible microplastic contamination. Fish were dissected carefully using metal dissecting utensils, and gut contents were collected into glass containers. 10\% $\mathrm{KOH}$ was added three times the volume of gut content, mixed well with a clean glass rod, and kept covered for approximately three weeks until the 


\section{R. R. M. K. P. Ranatunga et al}

tissues are digested (Modified from Alexandre et al. 2016). The solution was then vacuum-filtered and followed the same procedure used for sand samples. In addition, $1000 \mathrm{ml}$ of ultra-pure water was filtered and used as the blank experiment. The same procedure was followed in order to evaluate the possible contamination of microplastics during sample processing in the laboratory environment.

\section{Data collection and analysis}

Particle counts for the $1-5 \mathrm{~mm}$ category microplastics were obtained for each sample considering the depth (surface and subsurface), type (fiber, fragment, foam, and pellet), the region of the beach (vegetation, high-tide, and low-tide), and colour (blue, black, green, red, white and other) by visual observations. A hot-needle test was performed to confirm the suspected particles for microplastics. The average abundance (or percentage abundance) of microplastics in each category was calculated and illustrated graphically. A heated needle was brought near the suspected particle, and if the suspected particle melts and curl, it was determined as microplastic.

Polymer types for $<1 \mathrm{~mm}$ category microplastics from beach sand and fish gut samples were determined using Furrier-Transform Infra-Red (FTIR) Spectroscopy (Thermo Scientific Nicolet iS 10). Due to financial and analytical constraints, only a limited number of a representative sample from each category was subjected to FTIR analysis. Spectra obtained from the FTIR were compared with the built-in library and literature sources to confirm the polymer type.

MINITAB version 17.0 and Microsoft Excel 2016 were used for the descriptive statistics and General Linear Model analysis.

\section{RESULTS}

The abundance of $1-5 \mathrm{~mm}$ category microplastics in beach sand is presented in Figure 3. The highest mean abundance was recorded in Pitipana (7.2 \pm 7.66 particles $/ \mathrm{m}^{3}$ ) whereas $2.8 \pm 1.30$ particles $/ \mathrm{m}^{3}$ in Dūwana and $5.2 \pm 3.77$ particles $/ \mathrm{m}^{3}$ in Catamaran (Figure 4). The General Linear Model results indicate there is no statistically significant difference in the abundance of microplastics with sampling months $(p>0.05)$ or with study sites $(p>0.05)$.

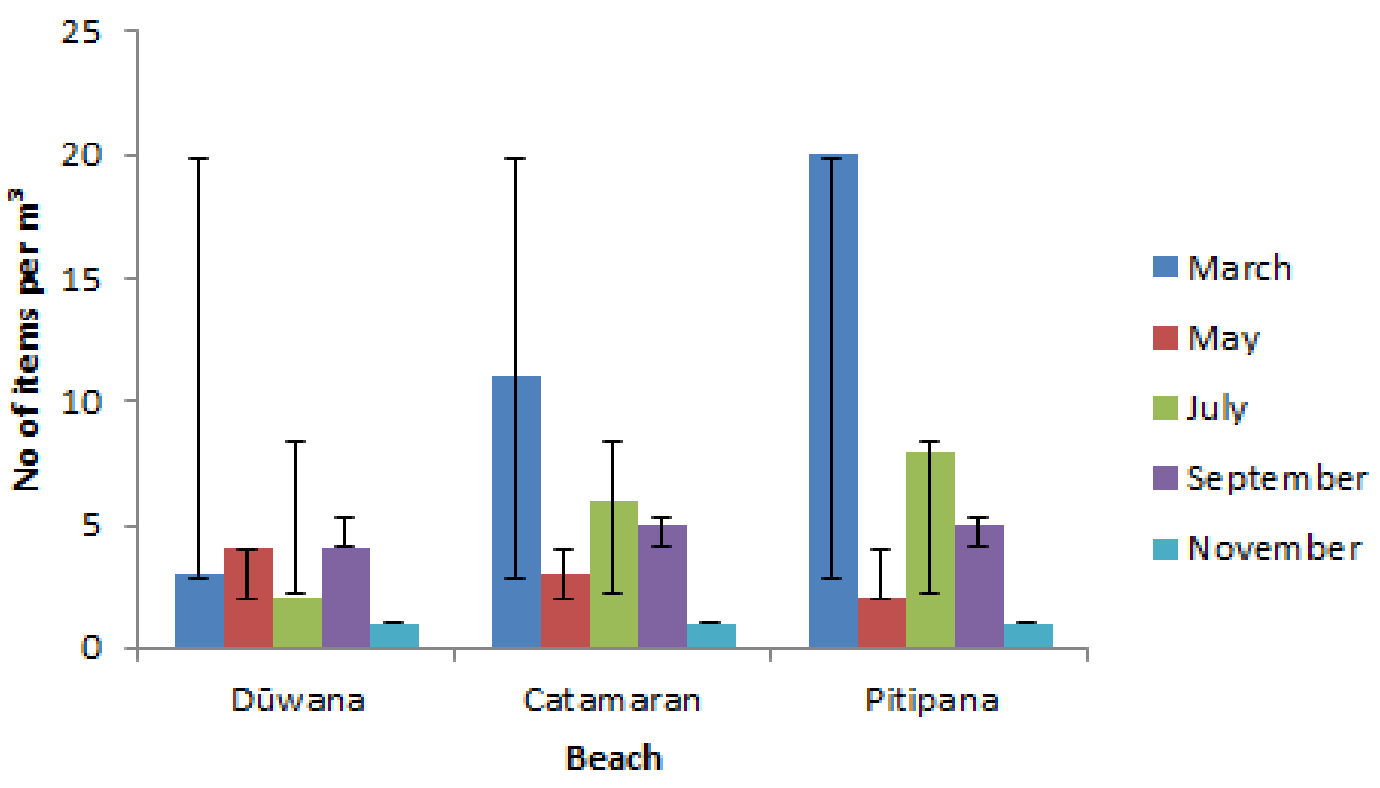

Fig 3 Abundance of 1- 5mm category microplastics in beach sand 


\section{R. R. M. K. P. Ranatunga et al}

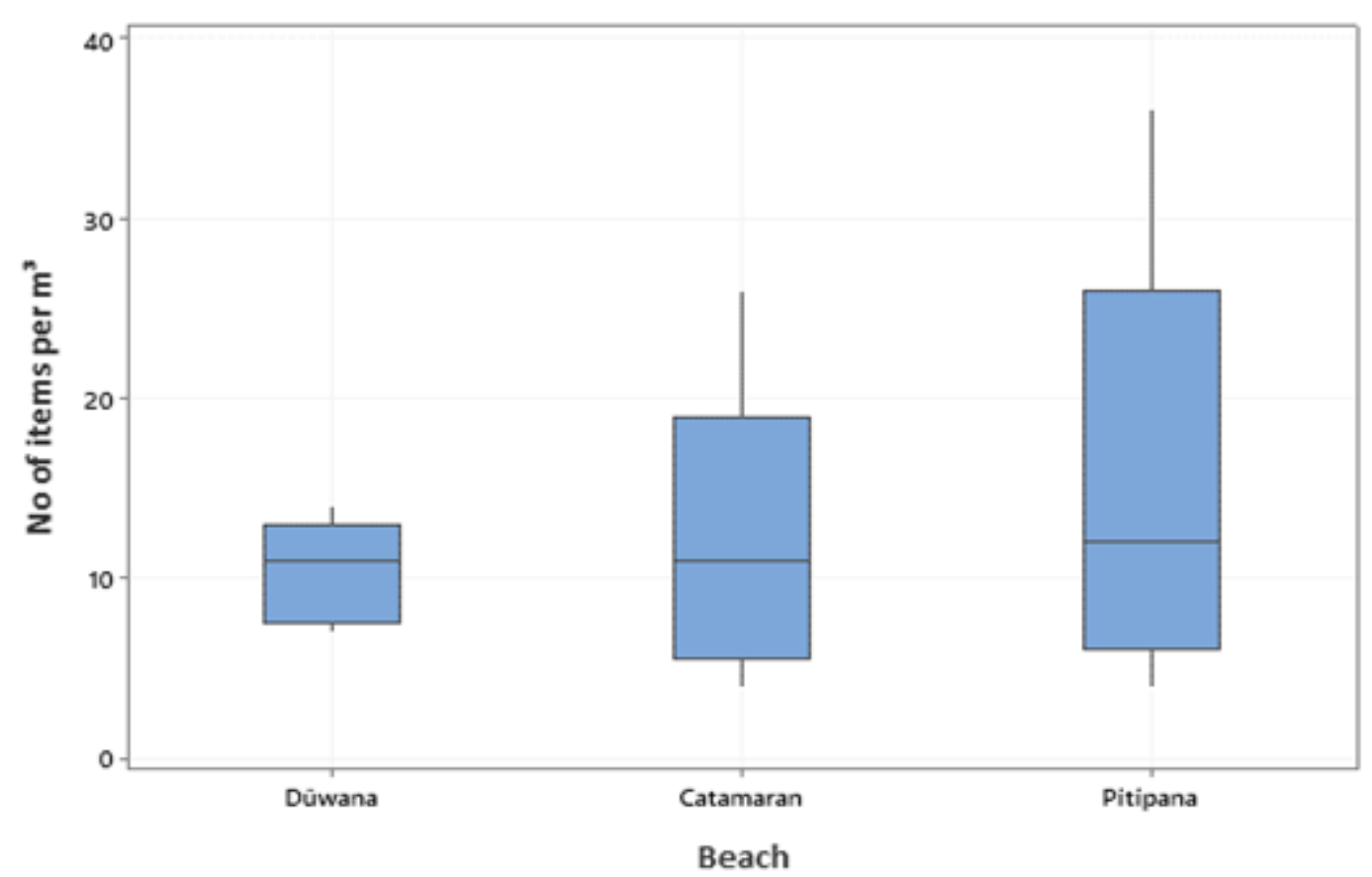

Fig 4 Box plot for the mean abundance of 1-5mm category microplastics in beach sand

Foam, fragment, and fibers were the microplastic types recorded in the $1-5 \mathrm{~mm}$ category (Figure 5). But no pellets were found in any of the samples. Fragments were abundant in Catamaran and Dūwana beaches $(92.3 \%$ and $92.9 \%$, respectively), while foams were the only type recorded in Pitipana (100\%). Microplastics found during the present study are suggested to be having a secondary origin. Most importantly, pellets that are considered as primary microplastics, were not found in any of the study sites.

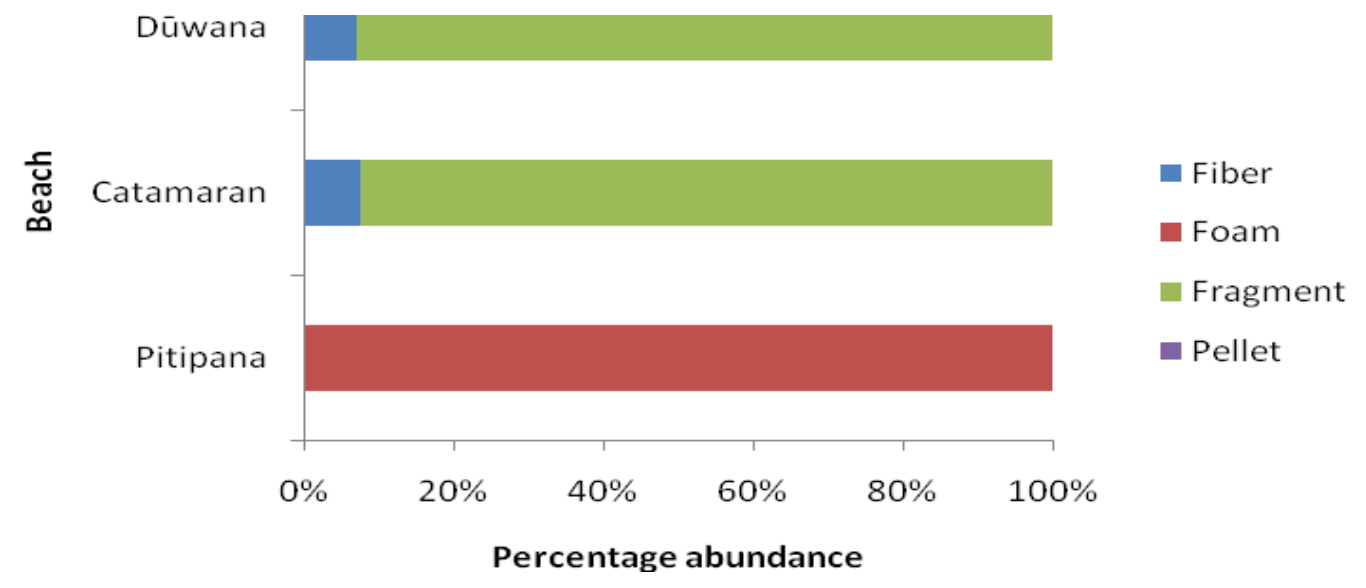

Fig 5 Geometry of $1-5 \mathrm{~mm}$ category microplastics from beach sand

Microplastics of $1-5 \mathrm{~mm}$ - size belonging to six colour categories (blue, black, red, green, white, and other) were recorded in the study (Figure 6). In terms of overall abundance, white-coloured particles were dominant (47\%) followed by blue
(16\%) and black (16\%) colours. Microplastics of white colour were dominant in Pitipana beach (97\%), blue colour in Catamaran beach (38\%), and black colour in Dūwana beach (57\%). 


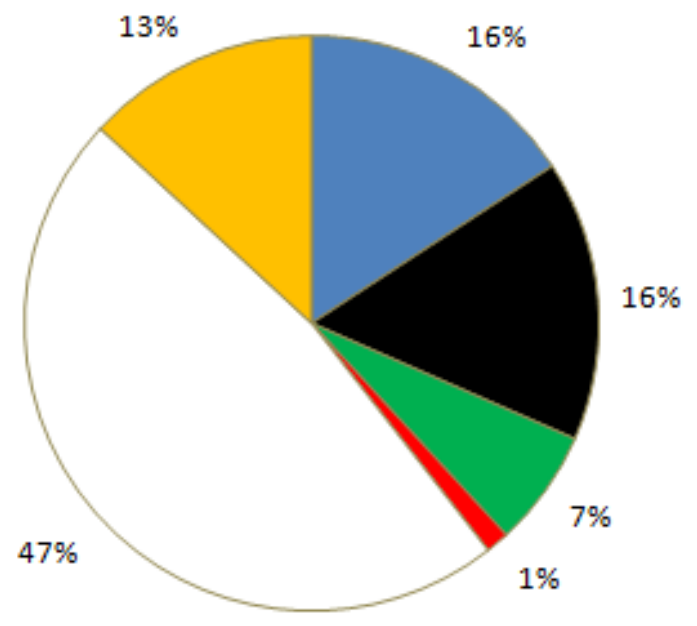

Blue

Black

Green

ned

$\square$ White

$\square$ Other

Fig 6 Colour of 1-5mm category microplastics from beach sand

The majority of the $1-5 \mathrm{~mm}$ category microplastics $(85 \%)$ were recorded from surface samples, and a lesser abundance was observed in subsurface samples (Figure 7).
Microplastics of 1-5mm- size were reported in all three regions (vegetation, high-tide, and lowtide), and comparatively higher values were recorded from the vegetation area (Figure 8).

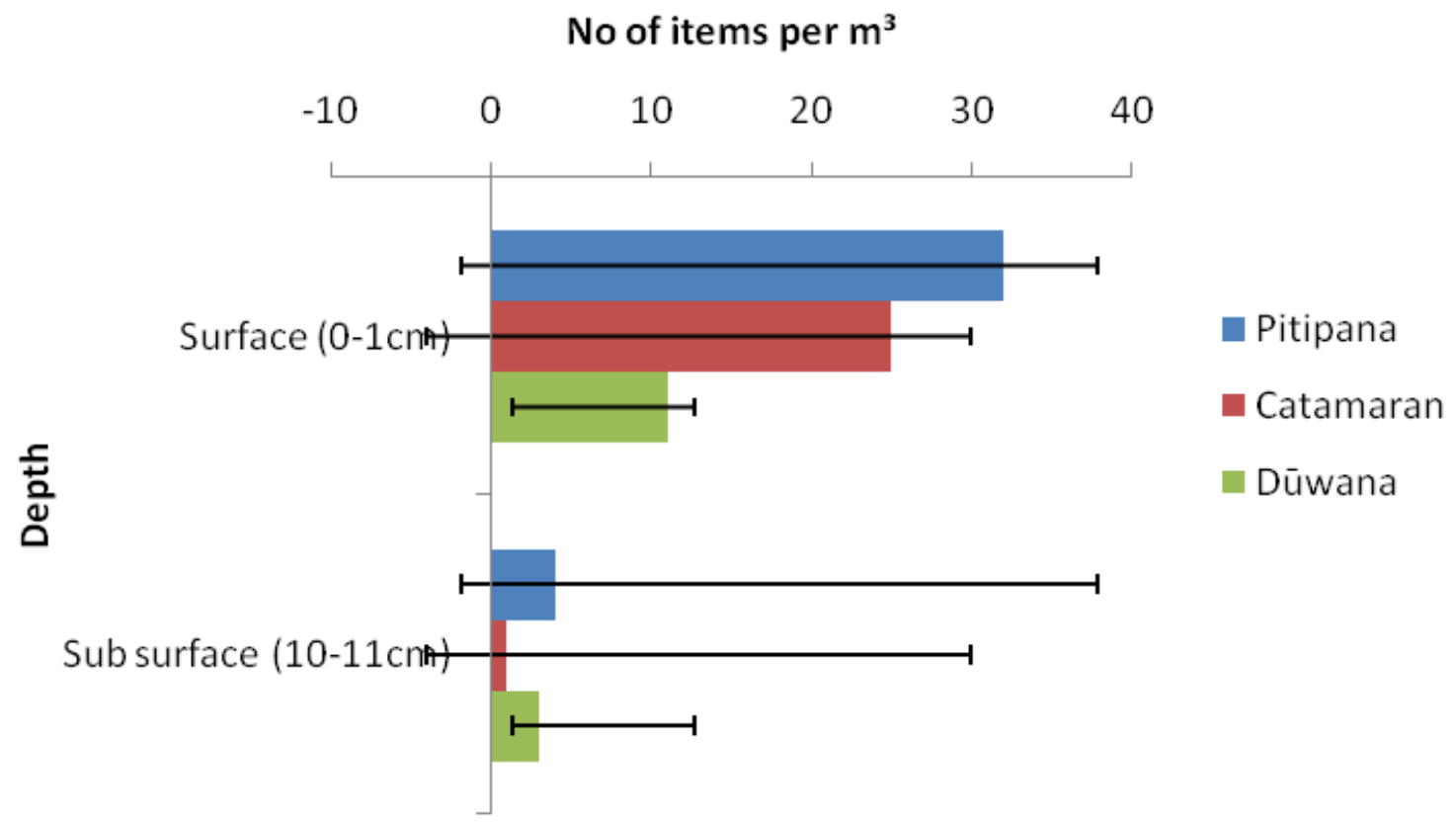

Fig 7 Abundance of 1- 5mm- category microplastics in beach sand vs. depth 


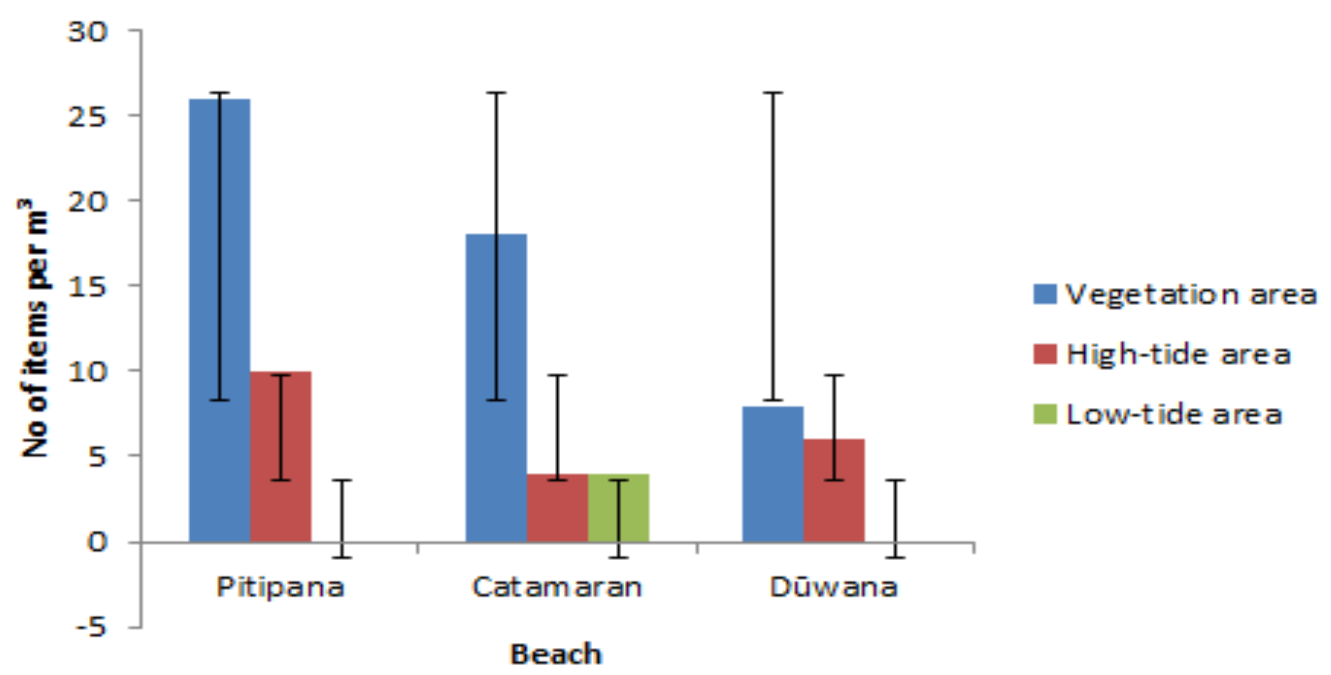

Fig 8 Abundance of 1- 5mm- category microplastics in beach sand vs. region

Major polymer types identified of $\leq 1 \mathrm{~mm}$ polyester and polypropylene were recorded from microplastics found in beach sand samples were Dūwana (Table 1). Figure 9(a) and 9(b) FTIR PVC, Acrylonitrile Butadiene Styrene (ABS), spectra were obtained for polyester particles from polyester, polyethylene and polypropylene. PVC Catamaran and Dūwana beach sand, respectively. and ABS were recorded from Pitipana, polyester, Figure 9(c) FTIR spectrum was obtained for PVC polyethylene, and PVC from Catamaran and from Catamaran.

Table 1 Polymer types detected in sampling locations during the study: Available (+), Not available (-)

\begin{tabular}{|c|c|c|c|c|c|c|}
\hline & & March & May & July & September & November \\
\hline \multirow{6}{*}{ Pitipana } & $\mathrm{PVC}$ & + & + & + & + & + \\
\hline & Acrylonitrile & & & & & \\
\hline & $\begin{array}{l}\text { Butadiene Styrene } \\
\text { (ABS) }\end{array}$ & - & + & - & - & + \\
\hline & Polyester & - & - & - & - & - \\
\hline & Polyethylene & - & - & - & - & - \\
\hline & Polypropylene & - & - & - & - & - \\
\hline \multirow{5}{*}{ Catamaran } & PVC & - & - & + & - & - \\
\hline & Acrylic & - & - & - & - & - \\
\hline & Polyester & + & + & - & + & + \\
\hline & Polyethylene & - & - & - & + & + \\
\hline & Polypropylene & - & - & - & - & - \\
\hline \multirow{5}{*}{ Dūwana } & PVC & - & - & - & - & - \\
\hline & Acrylic & - & - & - & - & - \\
\hline & Polyester & + & + & + & + & + \\
\hline & Polyethylene & - & - & - & - & - \\
\hline & Polypropylene & - & + & + & - & + \\
\hline
\end{tabular}


(a)

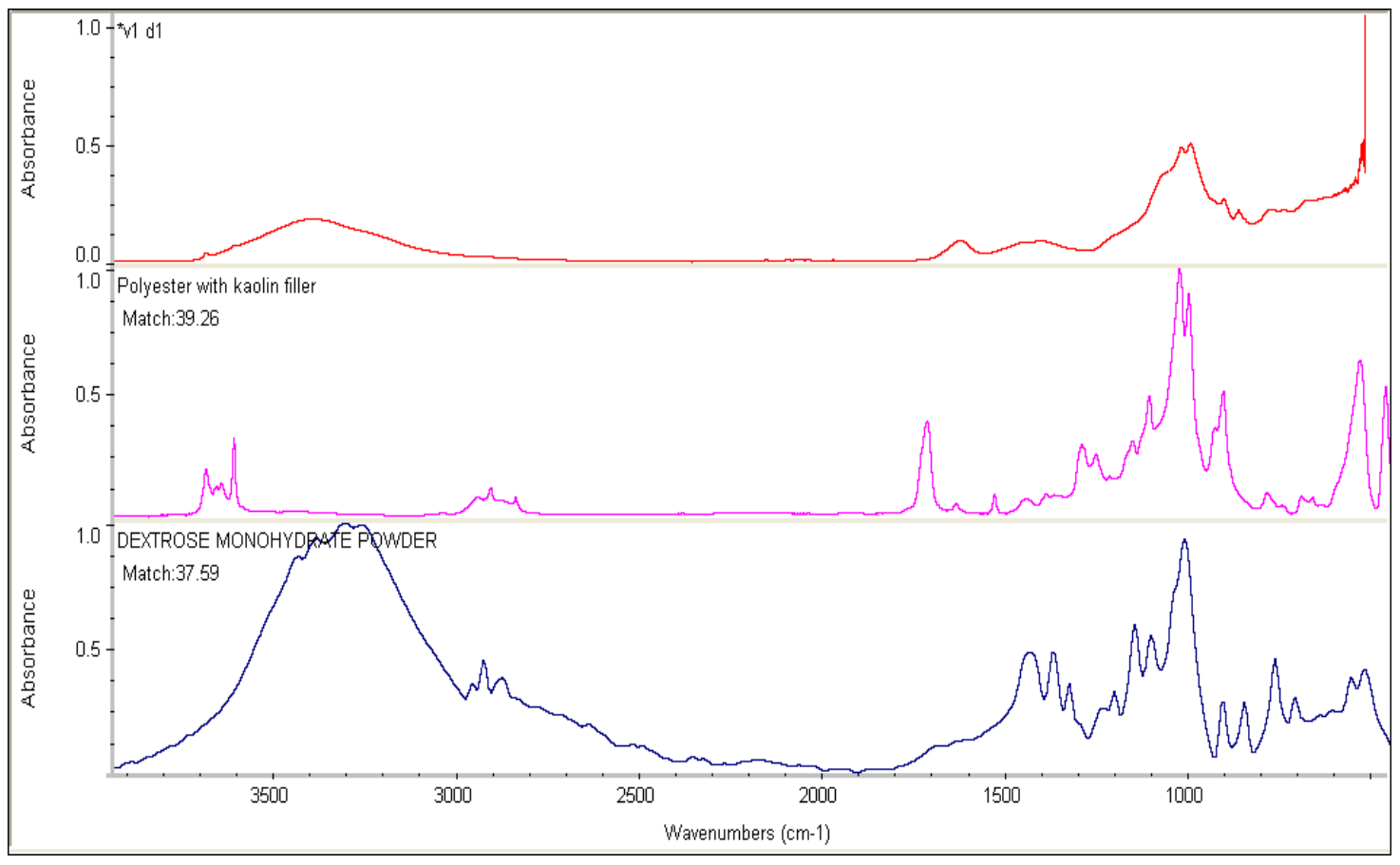

(b)

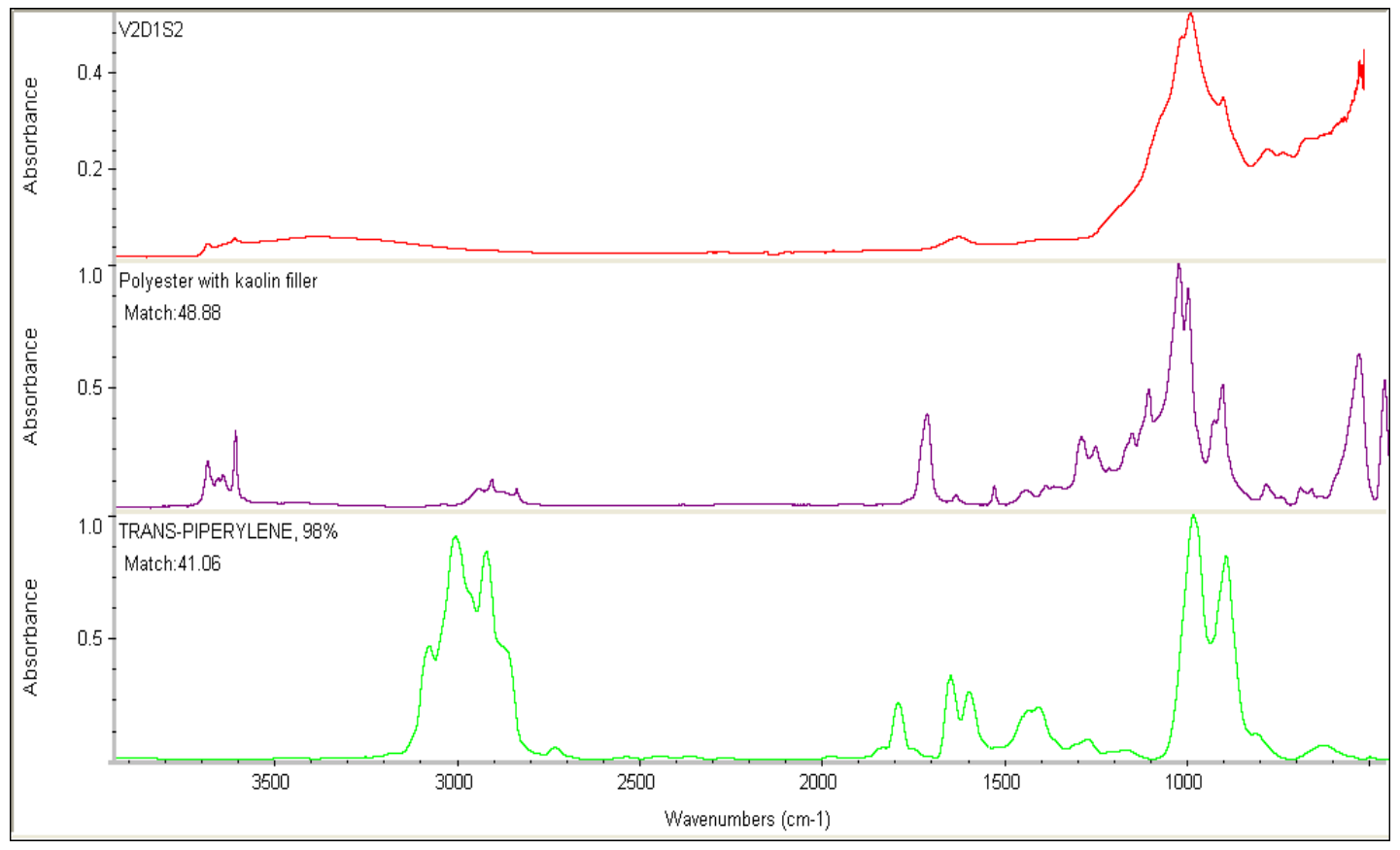


(c)

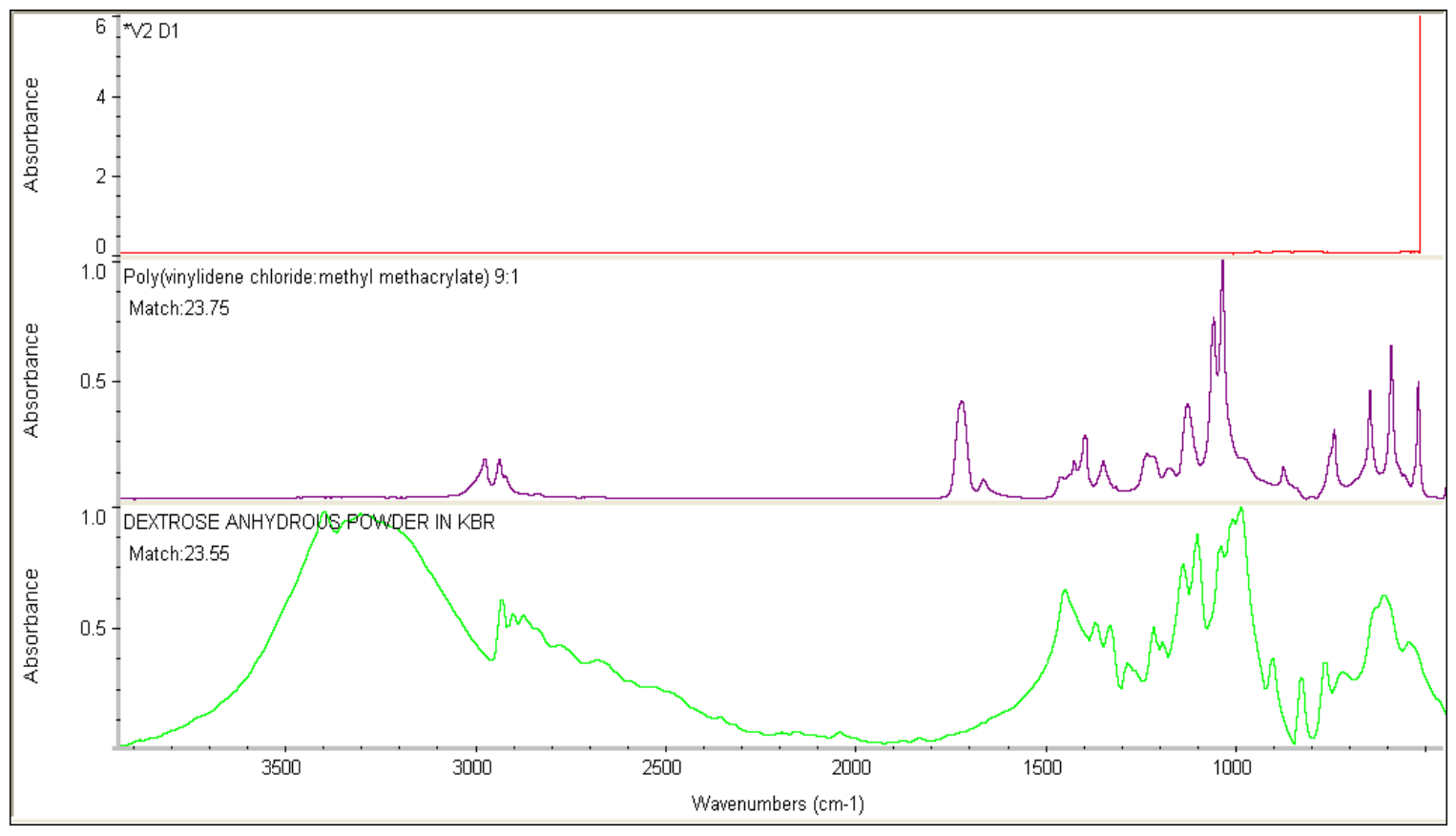

Fig 9 FTIR spectrum obtained for polyester (a) (Catamaran); (b) (Dūwana); and for PVC (c) (Catamaran)

Polyethylene and polypropylene were the polymer microplastics in near-shore waters off Negombo types identified from the fish gut sample of Sardinella gibbosa, suggesting contamination of (Figure 10(a) and 10(b)).

(a)

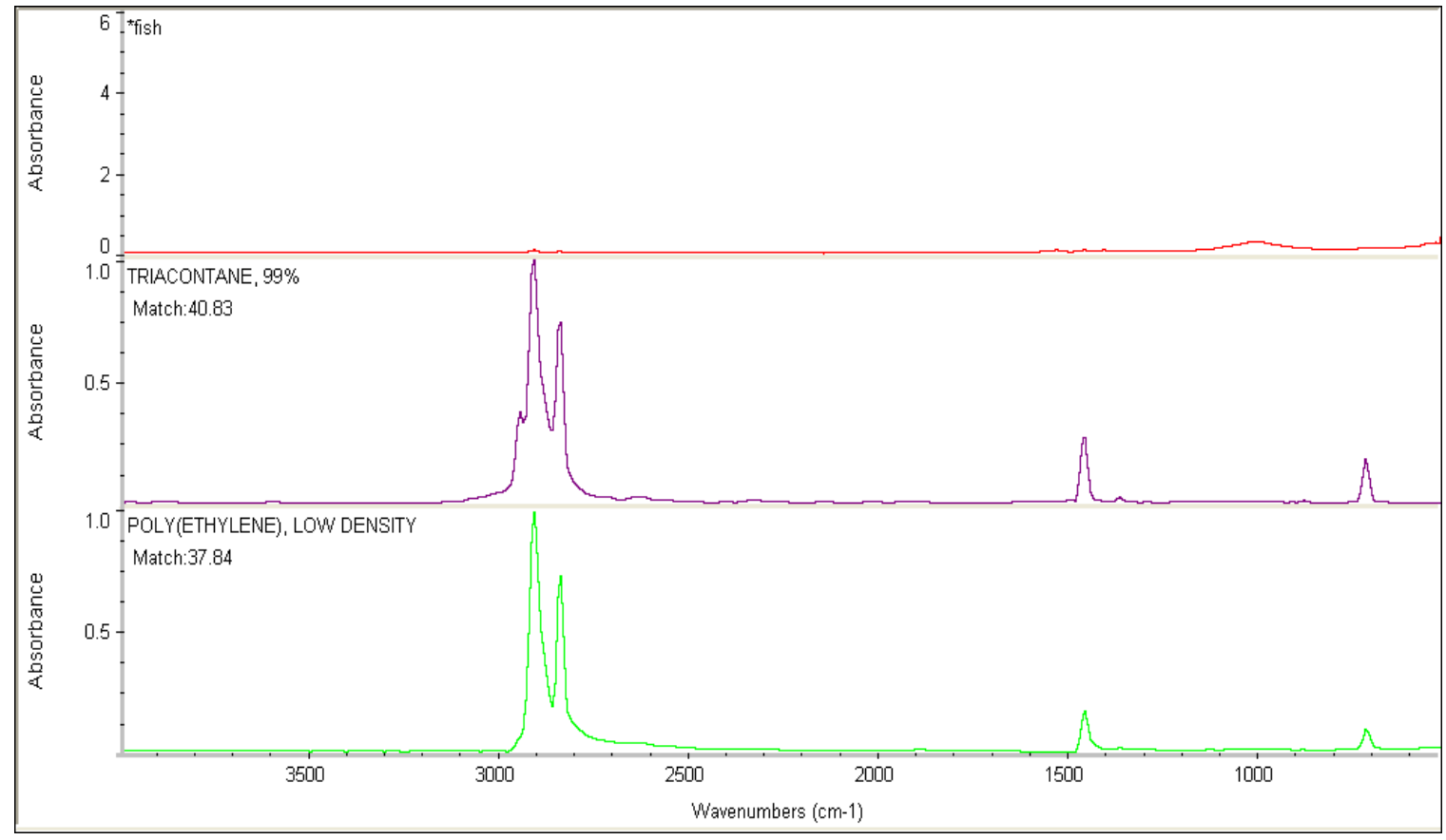


(b)

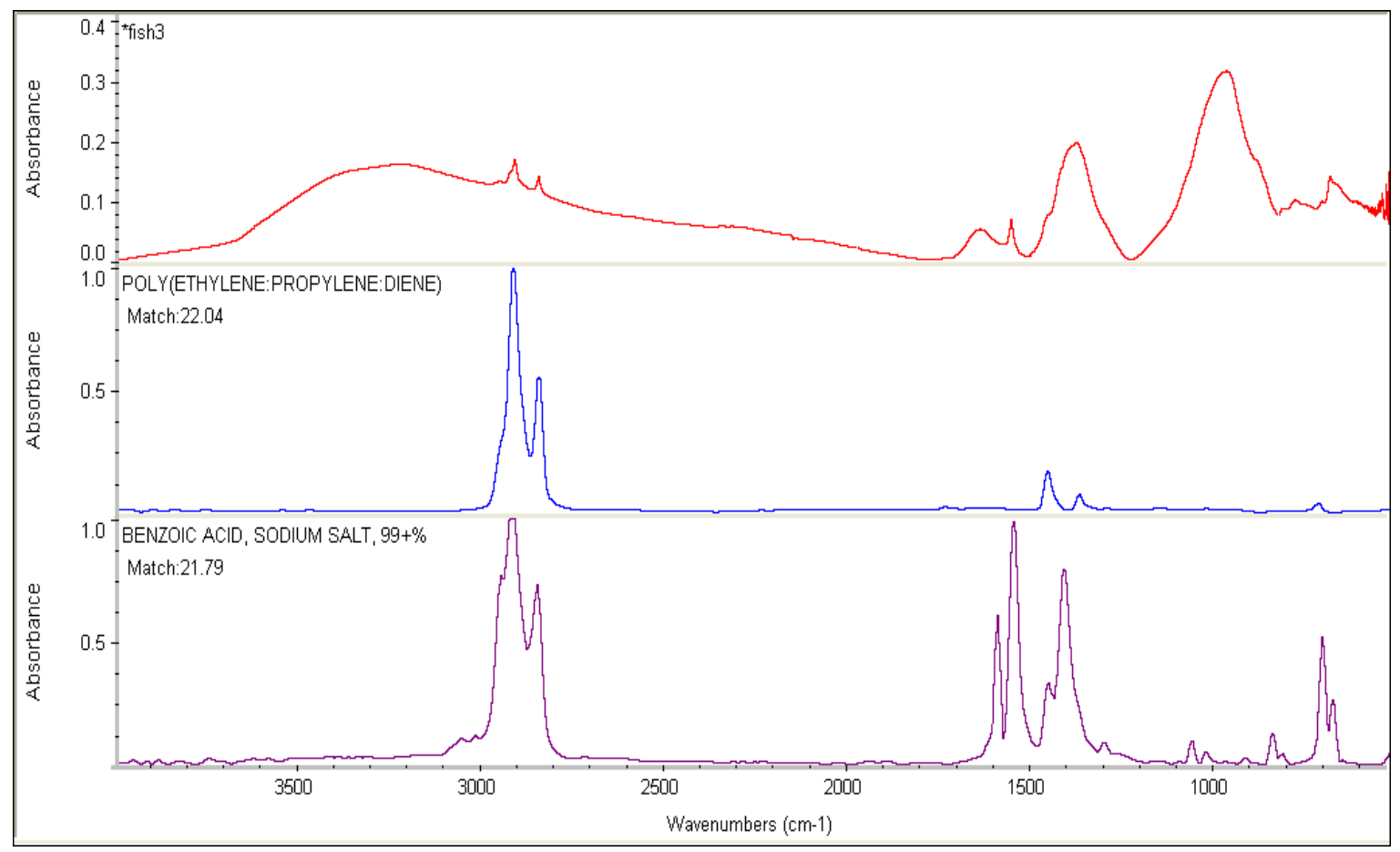

Fig 10 FTIR spectrum obtained for polyethylene in (a) and for polypropylene (b) in fish gut sample

\section{DISCUSSION}

\section{Abundance}

Higher microplastic abundance was observed during the first sampling in March from Pitipana and Catamaran beaches, which may be due to the long-term deposition of microplastics, whereas Dūwana beach was subjected to flushing with rain since it is next to the Maha Oya river mouth. During the sampling in November, the heavy rain might be the reason for the lower abundance of microplastics in all three sites. Microplastics presence in a particular location is a combined result of several factors such as geological characteristics, wind and wave patterns, anthropogenic activities, etc., (Weerakoon et al. 2018; Viraj et al. 2019). According to Alomar et al. (2016), strong currents and wind play a significant role in transporting buoyant litter from far away sources to deposition zones. The possibility of microplastics accumulation is higher in complex geomorphological areas with favourable hydrodynamic conditions. Therefore, unique geographical characteristics in each beach may also play an important role in microplastic occurrence.

\section{Possible sources of microplastics}

According to OSPAR (2009), microplastics originated from fishery-related activities include discarded, lost, or abandoned fishing gear such as plastic monofilament and nylon nets. These fall into fiber type of microplastics. In Catamaran beach, fragments were dominant over fibers, suggesting less influence of fishery-related operations. The non-appearance of pellets in any sampling sites could be due to the absence of commercial plastic production in the area. According to Rochman et al. (2015), polyethylene, polypropylene, and polystyrene are commonly used polymers in producing primary microplastics. Polyethylene and polypropylene were recorded in Catamaran and Dūwana beaches (Table 1). However, there is no evidence to declare that such polymers are due to the presence of primary microplastics. Therefore, it can be concluded that all microplastics present in study sites may have a secondary origin (i.e., breakdown of plastics). 


\section{Colour of microplastics}

Colour is considered an intrinsic property that supports visual identification of microplastics from other debris types and important in identifying potential sources. Katsanevakis (2008) reported the effect of colour in the ingestion of microplastics by some marine organisms. Castro et al. (2016) reported that $60 \%$ of the microplastic collected in water samples from Jurujuba (Brazil) were bluecoloured, resulting from the degradation of blue gallon bottles used to support mussel cultivation in the area. Koongolla et al. (2018) suggest that the blue and green microplastics reported from the southern coast of Sri Lanka could be fragments derived from the monofilament fishing lines. Therefore, the colour of microplastic particles suggests possible sources where they can derive. The presence of a variety of colours suggests a contribution from a variety of microplastics sources.

\section{Beach sand sampling depth}

The results show a decrease in microplastic abundance with increasing depth. Turra et al. (2014) have discussed several reasons for such a pattern. The surface sand layer is constantly in contact with seawater. Therefore, microplastics that are carried by the seawater may have a higher possibility to deposit in top layers than subsurface layers. Also, most of the lower waterline microplastics have a higher possibility of washing away by the next wave to the open ocean rather than depositing in the sand. Kunz et al. (2016) argued that there was no significant relationship between particles and depth within beach sand.

\section{Microplastic abundance with beach region}

According to Browne et al. (2011), debris from the sea tends to accumulate in the high-tide area, whereas land-based debris accumulates in the vegetation area. Therefore, a higher abundance of microplastics in the vegetation area may suggest higher amounts of land-based debris. Surprisingly, Pitipana beach, which is relatively isolated and narrow with less human influence, reported the highest number of $1-5 \mathrm{~mm}$ category microplastics in the vegetation area (72\%). Higher microplastic quantities are usually expected in populated or urbanized coastal areas with direct or indirect human influence. However, microplastic pollution has been reported even from remote areas and less human influence environments such as MPAs (Alomar et al. 2016). Pruter (1987) reported that marine ecosystems such as mid-ocean islands with no local plastic production facilities also reported a higher abundance of microplastics. Alomar et al. (2016) also provided evidence for such an exceptional scenario in Es Port and Santa Maria in Canberra Archipelago National MaritimeTerrestrial Park in the western Mediterranean. They suggest that the contaminants could have transferred from distant waters to deposition zones with favourable geographical characteristics and weather patterns. Therefore, a higher abundance of microplastics in comparatively less polluted areas suggests the importance of models to assess microplastics pollution by combining oceanographic factors along with biotic and abiotic factors.

\section{Polymer types of <1mm category microplastics}

Kunz et al. (2016) explained that the polymer types of microplastic could be used in identifying potential sources. For instance, polyester fibers are commonly used to produce textiles, bottles, films, and filters, while PVC is used in manufacturing window frames, inflatable pools, and pipes. Acrylonitrile butadiene styrene (ABS), a common thermoplastic polymer, is mainly used in rubber productions, while polyethylene is used in producing reusable bags, trays, containers, agricultural film, bottles, toys, etc. Polypropylene is used in the production of food packaging, sweet and snack wrappers, hinged caps, microwave-proof containers, pipes, automotive parts as well as in fishery-related applications (PlasticEurope 2016; Rodríguez-Seijo and Pereira 2017). Therefore, fishing and tourism-related activities in Catamaran beach may have contributed to the presence of polyester, polyethylene, and PVC in the beach sand. In the lower reach of Maha Oya, industries may have contributed to polyester and polypropylene microplastics reported from Dūwana. But the reasons for the presence of PVC and ABS polymers in Pitipana beach is not clear.

\section{Microplastic contamination in Sardinella gibbosa}

Planktivorous fish such as goldstrip sardine (Sardinella gibbosa) is known to falsely identify microplastics as food items and prey on them. 
Meegahakotuwa et al. (2020) reported the abundance of microplastics in coastal waters off Maha Oya estuary, near Dūwana as high as $11.84 \pm$ 2.62 particles $\mathrm{dm}^{3}$ and confirmed the presence of polyethylene, polypropylene, and polystyrene using Raman spectroscopic analysis. Which suggests the possibility of microplastic ingestion in biota inhabiting the coastal waters. Since microplastics are rarely degradable, non-excreting, and longlasting, the possibility to accumulate along the food chain is higher (Gregory 2009; Fendall and Sewell 2009; Frias et al. 2010; Alomar et al. 2016) which would pose huge health risks even to humans.

\section{CONCLUSIONS}

Microplastics of 1-5mm size range were present in both beach sand and fish gut contents, providing evidence for microplastic contamination in Negombo coasts of Sri Lanka. The highest mean abundance of microplastics was reported from Pitipana. No significant difference was observed in abundance among locations or with time. Fiber, foam, and fragments of white, black, or blue colour polyester, polypropylene, and PVC microplastics were dominant on the surface layer. However, the absence of primary microplastics suggests that the microplastics recorded are secondary in origin. The majority of microplastics found in the vegetation area suggests possibility of land-based contamination. The presence of microplastics in fish gut samples suggests the potential bioaccumulation of microplastics in marine biota. Higher amounts of microplastics recorded in comparatively less human-influenced beaches suggest the importance of combining the studies with models to assess microplastics pollution.

\section{ACKNOWLEDGMENTS}

The authors would like to extend immense gratitude to the Instrumental Centre, Faculty of Applied Sciences, University of Sri Jayewardenepura, for providing support in FTIR analysis and the Center for Marine Science and Technology for supporting the fieldwork and laboratory analysis.

\section{REFERENCES}

Alexandre D. A.L Cassone, L. Frere, L. Hermabessiere, C. Himber, E. Rinnert, G.
Riviere, C. Lambert, P. Soudant, A. Huvet, G. Duflos \& I. Paul-Pont 2016. Microplastics in seafood: Benchmark protocol for their extraction and characterization. Environmental Pollution 2015. 223-233.

Alomar, C., F. Estarellas \& S. Duedero 2016. Microplastics in the Mediterranean Sea: Deposition in shallow coastal sediments, spatial variation, and preferential grain size. Marine Environmental Research 115:1-10.

Andrady, A.L. 2011. Microplastics in the marine environment. Marine Pollution Bulletin 62: 1596-1605.

Athapaththu, A.M.A.I.K., A.M.G.A.D. Athawuda, P.C.B. Dias, A.P. Abeygunawardena, J.D.M. Senevirathna, G.G.N. Thushari, N.P.P. Liyanage \& S.C. Jayamanne 2019. Assessment of suspended plastic levels in surface water of Southern coastal belt in Sri Lanka. UWU conference proceedings, International Research Conference of UWU-2019.

Athawuda A.M.G.A.D., H.B. Jayasiri, G.G.N. Thushari \& K.P.G.K.P. Guruge 2020. Quantification and morphological characterization of plastic litter $(0.30-100 \mathrm{~mm})$ in surface waters of off Colombo, west coast of Sri Lanka. Environmental Monitoring and Assessment 192: 509.

Balasubramaniam, M. \& A.D. Phillott 2016. Preliminary observations of microplastics from beaches in the Indian Ocean. Indian Ocean Turtle Newsletter No. 23, Asian University for Women, Chittagong, Bangladesh.

Barnes, D.K., F. Gaglani, R.C. Thompson \& M. Barlaz 2009. Accumulation and fragmentation of plastic debris in global environments. Philosophical Transactions of the Royal Society B 364: 1985-1998.

Betts, K., 2008. Why small plastic particles may pose a big problem in the oceans. Environmental Science and Technology 42: 8995.

Blight, L.K. \& A.E. Burger 1997. Occurrence of plastic particles in sea birds from the Eastern North Pacific. Marine Pollution Bulletin 34(5): 323-325.

Bonin, T., R. Dris, J. Gasperi, V. Rocher \& B. Tassin 2014. Assessment of floating plastic debris in surface water along the Seine River. Environmental Pollution 195: 163-166. 


\section{R. R. M. K. P. Ranatunga et al}

Browne, M.A., P. Crump, S.J. Niwen, E. Teuten, A. Tonkin, T. Galloway \& R. Thompson 2011. Accumulation of microplastic on shoreline worldwide: Sources and sinks. Environmental Science and Technology 45: 9175-9179.

Buchanan, J.B. 1971. Pollution by synthetic fibers. Marine Pollution Bulletin 2(2):23.

Carpenter, E.J., S.J. Anderson, G.R. Harvey, H.P. Miklas \& B.B. Peck 1972. Polystyrene spherules in coastal water. Science 178: 749750 .

Carpenter, E.J. \& Jr K.L. Smith 1972. Plastics on the Sargasso sea surface. Science 175: 12401241.

Castro, R.O., M.L. Silva, M.R.C. Marques \& F.V. de Araujo 2016. Evaluation of Microplastics in Jurujuba cove, Niteroi, R.J., Brazil, an area of mussels farming. Marine Pollution Bulletin 110(1): 555-558.

Claessens, M., S. De Meester, L. Van Landuyt, K. De Clerck \& C.R. Janssen 2011. Occurrence and distribution of microplstics in marine sediments along the Beigian coast. Marine Pollution Bulletin 62(10): 2199-2204.

Collignon, A., J.H. Hecq, F. Galgani, P. Voison, F. Collard \& A. Goffart 2012. Neustonic microplastic and zooplankton in the North Western Mediterranean Sea. Marine Pollution Bulletin 64(4): 861-864.

Colton, J.B. \& F.D. Knapp 1974. Plastic particles in surface waters of the northwestern Atlantic. Science 185: 491-497.

Costa, M.F., J.A. Ivar do Sul, J.S. Silva-Cavalcanti, M.C.B. Arujo, A. Splenger \& P.S. Turinho 2010. On the importance of size of plastic fragments and pellets on the strandline: A snapshot of a Brazilian beach. Environmental Monitoring Assessment 164(1-4): 299-304.

Dharmadasa, W.L.S.S., A.L. Andrady, P.B.T.P. Kumara \& C.S. Gangabadage 2019. Assessment of microplastics contamination in marine protected areas in Southern Sri Lanka. National Aquatic Resources Research and Development Agency (NARA), Scientific sessions 2019.

Duis, K. \& A. Coors 2016. Microplastics in the aquatic and terrestrial environment: sources (with a specific focus on personal care products), fate and effects. Environmental Sciences Europe 28: 2.
Fendall, L.S., \& M.A. Sewell 2009. Contributing to marine pollution by washing your face. Microplastics in facial cleansers. Marine Pollution Bulletin 58(8): 1225-1228.

Frias, J.P.G.I., P. Sobral \& A.M. Ferreira 2010. Organic pollutant in microplastics from two beaches of the Portuguese coastal waters. Marine Pollution Bulletin 60: 1988-1992.

Gago, J., A. Filgueiras, M.L. Pedrotii, M. Caetano \& J. Frias 2018. Standardized protocol for monitoring microplastics in seawater. JPIOceans BASEMAN project.

G.E.S.A.M.P. 2015. Sources, fate and effects of microplastics in the marine environment: a global assessment. Kershaw, P. J. (ed), IMO/FAO/UNESCOIOC/UNIDO/WMO/IAEA/UN/UNEP/UNDP Joint group of Experts on the Scientific Aspects of Marine Environmental Protection. 2015. Reports and Studies: 90-96.

Goldstein, M.C., M. Rosenberg \& L. Cheng 2012. Increased oceanic microplastic debris enhances oviposition in an endemic pelagic insect. Biology Letters 8(5): 817-820.

Graham, E.R. \& J.T. Thompson 2009. Deposit and suspension-feeding sea cucumbers (Echinodermata) ingest plastic fragments. Journal of Experimental Marine Biology and Ecology 368(1): 22-29.

Gregory, M.R. 1996. Plastic 'scrubbers' in handcleansers: a further (and minor) source for marine pollution identified. Marine Pollution Bulletin 32: 867-871.

Gregory, M.R. 2009. Environmental implications of plastic debris in marine settings-entanglement, ingestion, smothering, hangers-on, hitch-hiking and alien invasions. Philosophical Transactions of the Royal Society B 364: 2013-2025.

Hanke G.F., F. Galgani, S.S. Werner, L. Oosterbaan, P. Nilsson \& D. Fleet 2013. MSFD GES technical subgroup of marine litter. Guidance on monitoring of marine litter in European seas. Luxemburg: Joint Research Center-Institute for Environment and sustainability, Publications office of European Union.

Hardesty, B.D. \& C. Wilcox 2011. Understanding the types, sources and at-sea distribution of marine debris in Australian waters. Final Report to the Department of Sustainability, Environment Water, Population and 


\section{R. R. M. K. P. Ranatunga et al}

Communities. Wealth from oceans flagship.

C.S.I.R.O., Australia.

Hidalgo-Ruz, V., L. Gutow, R.C. Thompson \& M. Thiel 2012. Microplastics in the marine environment: A review of the methods used for identification and quantification. Environmental Science and Technology, 46, 6: 3060-3075.

Ivar do Sul, J.A., M.F. Costa, M. Barletta F.J.A. Cysneiros 2013. Pelagic microplastics around an archipelago of the equatorial Atlantic. Marine Pollution Bulletin 75: 305-309.

Imhof, H.K, C. Laforsch, A.C. Wiesheu, J. Schmid, P.M. Anger, R. Neissner \& N.P. Ivleva 2016. Pigments and plastic in limnetic ecosystems: A qualitative and quantitative study on microparticles of different size classes. Water Research 98: 64-74.

Jambeck, J.R., M. Perryman, R. Geyer, C. Wilcox, T.R. Slegler, K.L. Law, R. Narayan \& A. Andrady 2015. Plastic waste inputs from land into the ocean. Science 347: 768-771.

Jang, Y.C., R.R.M.K.P. Ranatunga, J.Y. Mok, K.S. Kim, S.Y. Hong, Y.R. Choi \& A.J.M. Gunasekara 2017. Composition and abundance of marine debris stranded on the beaches of Sri Lanka - Results from the first island-wide survey. Marine Pollution Bulletin 128: 126131.

Jayasiri, H.B., C.S. Purushothaman \& A. Vennila 2013. Quantitative analysis of plastic debris on recreational beaches in Mumbai, India. Marine Pollution Bulletin 77: 107-112.

Katsanevakis, S. 2008. Marine Debris, a Growing Problem: Sources, Distribution, Composition, and Impacts. In: Ofer, T.N. (Ed.), Marine Pollution: New Research, Nova Science Publishers, New York, 53-100 pp.

Koongolla, J.B., A.L. Andrady, P.B. Terney Pradeep Kumara \& C.S. Gangabadage 2018. Evidence of microplastics pollution in coastal beaches and waters in southern Sri Lanka. Marine Pollution Bulletin 137: 277-284.

Kunz, A., B.A. Walther, L. Lowemark \& Y.C. Lee 2016. Distribution and quantity of microplastic on sandy beaches along the northern coast of Taiwan. Marine Pollution Bulletin 111(1-2): 126-135.

Law, K.L., S. Moret-Ferguson, N.A. Maximenko, G. Proskurowski, E.E. Peacock, J. Hafner \& C.M. Reddy 2010. Plastic accumulation in the
North Atlantic subtropical gyre. Science 329(5996): 1185-1188.

Lee, J., S. Hong, Y.K. Song, S.H. Hong, Y.C. Jang, M. Jang, N.W. Heo, G.M. Han, M.J. Lee \& D. Kang 2013. Relationships among the abundances of plastic debris in different size classes on beaches in South Korea. Marine Pollution Bulletin 77: 349-354.

Lenz, R., K. Enders \& T.G. Nielsen 2016. Microplastic exposure studies should be environmentally realistic. Proceedings of the National Academy of Sciences of the United States of America 113(29): E4121-E4122.

Meegahakotuwa, B.M.B., R.R.M.K.P. Ranatunga \& A.J.M. Gunasekara 2020. Microplastic contamination in coastal waters off Maha Oya estuary in Negombo. Uni-In-Alliance 2020: 49.

Moore, C.J. 2008. Synthetic polymers in the marine environment: a rapidly increasing long-term threat. Environmental Research 108(2): 131139.

National Oceanographic and Atmosphere Administration, 2008. Proceedings of the International research workshop on the occurrence, effects, and fate of microplastic marine debris, NOAA, Silver Spring.

Nuelle, M.T., J.H. Dekiff, D. Remy \& E. Fries 2014. A new analytical approach for monitoring microplastics in marine sediments. Environmental Pollution 184: 161-169.

Obbard, R.W., S. Sadri, Y.Q. Wong, A.A. Khitun, I. Baker \& R.C. Thompson 2014. Global warming releases microplastic legacy frozen in Arctic sea ice. Earth's future 2(6): 315-320.

OSPAR (2009). Marine litter in the Northeast Atlantic Region: Assessment and priorities for response. London, United Kingdom. 127 pp.

Patel, M.M., B.R. Goyal, S.V. Bhadada, J.S. Bhatt \& A.F. Amin 2009. Getting into the brain: Approaches to enhance brain drug delivery. C.N.S. Drugs 23: 35-58.

PlasticsEurope, 2016. Plastics-The Facts 2016: An analysis of European latest plastics production, demand and waste data: 1-38.

PlasticsEurope, 2019. Plastics-The Facts 2019: An analysis of European plastics production, demand and waste data: 1-42.

Pruter, A.T. 1987. Sources, quantities and distribution of persistent plastics in the marine ocean environment. In Plastics in the Sea: Selected papers from the sixth international 
ocean disposal system (D.A. Wolfe, ed.). Marine Pollution Bulletin 18: 305-310.

Ranatunga, R.R.M.K.P. \& K.P.R. Karunarathna 2018. First evidence of Microplastics in beach sand from Negombo, Sri Lanka and the potential accumulation in marine fish. International Conference on Multidisciplinary Approaches (iCMA), University of Sri Jayewardenepura.

Rochman, C.M., A. Tahir, S.L. Williams, D.V. Baxa, R. Lam, J.T. Miller, F.C. Teh, S. Werorilangi \& S.J. The 2015. Anthropogenic debris in seafood: Plastic debris and fibers from textiles in fish and bivalves sold for human consumption. Scientific reports 5: 14340.

Rodríguez-Seijo, A. \& R. Pereira 2017. Morphological and Physical Characterization of Microplastics. Comprehensive Analytical Chemistry 75: 49-66.

Ryan, P.J., C.J. Morre, J.A. van Franeker \& C.L. Moloney 2009. Monitoring the abundance of plastic debris in the marine environment. Philosophical Transactions of the Royal Society B 364: 1999-2012.

Sadri, S.S. \& R.C. Thompson 2014. On the quantity and composition of floating plastic debris entering and leaving the Tamar estuary, Southwest England. Marine Pollution Bulletin 81: 55-60.

Santos, I.R., A. Friedrich 7 J.A.I. do Sul 2009. Marine debris contamination along undeveloped tropical beaches from Northeast Brazil. Environmental Monitoring Assessment 148:455-162.

Song, Y.K., S.H. Hong, M. Jang, G.M. Han, M. Rani, J. Lee \& W.J. Shim 2015. A comparison of microscopic and spectroscopic identification methods for analysis of microplastics in Environmental samples. Marine Pollution Bulletin 93:202-209.

Thakshila, V.G.N. \& R.R.M.K.P. Ranatunga 2019. Evidence of microplastics contamination in surface waters and sediment of Kelani river estuary. Proceedings of the $24^{\text {th }}$ annual International Forestry and Environment Symposium 2019 of the Department of Forestry and Environmental Science, University of Sri Jayewardenepura, Sri Lanka: 68.

Tourinho, P.S., J.A.I. do Sul \& G. Fillrnann 2010. Is marine debris ingestion still a problem for the coastal marine biota of southern Brazil? Marine Pollution Bulletin 60: 396-401.

Turra, A., A.B. Manzano, R.J.S. Dias, M.M. Mahiques, L Barbosa, D. Balthazaar-Silva \& F.T. Moreira 2014. Three-Dimensional distribution of plastic pellets in sandy beaches: shifting paradigms. Scientific Reports 4(1): 4435.

Van Cauwenberghe, L., A. Vanreusel, J Mees \& C.R. Janssen 2013. Microplastics pollution in deep-sea sediments. Environmental pollution 182: 495-499.

Van Cauwenberghe, L., L. Devriese, F. Galgani \& J. Robbens and Janssen C.R. 2015. Microplastics in sediments: A review of techniques, occurrence and effects. Marine Environmental Research 111: 5-17.

Viraj, R.K.L., H.B. Jayasiri, N.L.D.H Devmali, C. Amarasiri \& H.P.S. Jayapala 2019. Plastic contamination in selected beaches of Sri Lanka with special reference to microplastics. National Aquatic Resources Research and Development Agency (NARA), Scientific sessions 2019.

Weerakkody, D.C.D. 2006. Salinity intrusion into the Maha Oya estuary and associated coastal waterways. Master's theses. Division of water resources engineering, Department of building and environmental technology, Lund University.

Weerakoon, W.R.W.M.A.P., T.B.D.T. Samaranayake, H.B. Jayasiri \& K. Arulananthan 2018. Quantitative analysis of micro-plastic contamination in beach sand at the Western and Southwestern coastal stretches in Sri Lanka. National Aquatic Resources Research and Development Agency (NARA), International Scientific sessions 2018.

Weerakoon, W.R.W.M.A.P., B.E. Grosvik, P. Dalpadado, H.B.U.G.M. Wimalasiri, M.I.G. Rathnasuriya, K.A.D.A.T. Harischandra, R.R.A.R. Shirantha, H.M.T.C Madhushankha, W.A.D. Sampath, R.P.P.K. Jayasinghe, S.S. Gunasekara, K. Arulananthan, A. Totland, K.W. Indika, P.M.N. Mihirani, W.N.C Priyadharashani, K.R. Arrigo, G. Bianchi \& J.O. Krakstad 2019. Enumeration of microplastics in Sri Lankan waters: Preliminary findings from the R.V. Dr. Fridtj Nansen Ecosystem Survey, 2018. National Aquatic Resources Research and Development Agency 


\section{R. R. M. K. P. Ranatunga et al}

(NARA), Scientific sessions 2019.

Wieczorek, A.M., L. Morrison, P.L. Croot, A.L. Allcock, E. MacLoughlin, O. Savard, H. Brownlow, \& T.K. Doyle 2018. Frequency of microplastics in mesopelagic fishes from the Northwest Atlantic. Frontiers in Marine Science 5: 39.

Wijethunga, H.N.S., A.M.G.A.D. Athawuda, P.C.B. Dias, A.P. Abeygunawardene, J.D.M. Senevirathna., G.G.N. Thushari, N.P.P. Liyanage \& S.C. Jayamanne 2018. Screening the effects of microplastics on selected invertebrates along Southern belt in Sri Lanka: A preliminary approach to coastal pollution control. Proceedings of the International Research Conference of UWU-2019. 27.

Wright, S.L., R.C. Thompson \& T.S. Galloway 2013. The physical impacts of microplastics on marine organisms: A review. Environmental pollution 178: 483-492.

Woodall, L.C., A.W. Sanchez-Vidal, M. Canals, G.L.J. Patterson, R. Coppock, V. Sleight, A. Calafat, A.D. Rogers, B.E. Narayanaswamy \& R.C. Thompson 2014. The deep sea is a major sink for microplastic debris. Royal Society Open Science 1(4): 140317.

Yu, X., J. Peng, J. Wang, K. Wang \& S. Bao 2016. Occurrence of microplastics in the beach sand of the Chinese inner sea: The Bohai Sea. Environmental Pollution 214:722-730.

Yu, Y., D. Zhou, Z. Li \& C. Zhu 2018. Advancement and challenges of microplastic pollution in the aquatic environment: A review. Water Air and Soil Pollution 229: 140.

Zitko, V. \& M. Hanlon 1991. Another source of pollution by plastics: skin cleaners with plastic scrubbers. Marine Pollution Bulletin 22: 41-42. 